\title{
PRÁTICA PEDAGÓGICA E DOCÊNCIA: UM OLHAR A PARTIR DA EPISTEMOLOGIA DO CONCEITO
}

\author{
PRÁCTICA PEDAGÓGICA Y ENSEÑANZA: UNA MIRADA A LA \\ EPISTEMOLOGÍA DEL CONCEPTO
}

\section{PEDAGOGICAL PRACTICE AND TEACHING: A LOOK AT THE EPISTEMOLOGY OF THE CONCEPT}

\section{Sandra POTTMEIER ${ }^{1}$}

Luiz Herculano de Sousa GUILHERME ${ }^{2}$ Caique Fernando da Silva FISTAROL ${ }^{3}$

Prática pedagógica e docência: um olhar a partir da epistemologia do conceito, de autoria de Maria Amélia do Rosario Santoro Franco, doutora em Educação pela USP, professora titular e pesquisadora do Programa de Pós-Graduação em Educação da UCS, líder do grupo de pesquisa Práticas Pedagógicas: Pesquisa e Formação e vice-coordenadora da Cátedra Paulo Freire pela UCS, publicado no volume 97 da Revista Brasileira de Estudos Pedagógicos em 2016, é constituído por seis seções ${ }^{4}$, seguidas das considerações finais e referências, distribuídas em 17 páginas. Este ensaio discorre acerca dos princípios que fundamentam as práticas pedagógicas a partir de uma perspectiva histórico-crítica (SAVIANI, 2005).

Trata-se de uma leitura indispensável para os acadêmicos dos cursos de licenciatura e cursos de pós-graduação (lato sensu e stricto sensu), professores e pesquisadores que se interessam pela temática, sejam estes inscritos na área da Educação ou que pertençam a outras áreas do conhecimento.

\footnotetext{
${ }^{1}$ Universidade Federal de Santa Catarina (UFSC), Florianópolis - SC - Brasil. Doutoranda no Programa de PósGraduação em Linguística. ORCID: https://orcid.org/0000-0001-7328-8656. E-mail: pottmeyer@gmail.com

2 Instituto Federal de Santa Catarina (IFSC), Gaspar - SC - Brasil. Professor de Língua Portuguesa e Coordenador de Pesquisa e Inovação. E-mail: luizherculano@yahoo.com.br

${ }^{3}$ Secretaria Municipal de Educação de Blumenau (SEMED), Blumenau - SC - Brasil. Coordenador de Línguas Estrangeiras - Línguas Alemã e Inglesa. ORCID: https://orcid.org/0000-0001-7650-7324. E-mail: cfersf@gmail.com

41 - Práticas pedagógicas: ambiguidades e novos sentidos; 2 - Práticas educativas e práticas pedagógicas; 3 Diferentes concepções de pedagogia; diferentes concepções de práticas pedagógicas (Racionalidade pedagógica técnico-científica; Racionalidade pedagógica crítico-emancipatória); 4 - O que são, afinal, práticas pedagógicas?; 5 - Pedagogia e práticas pedagógicas; 6 - Princípios da prática pedagógica, na perspectiva crítica ( $a$ - As práticas pedagógicas organizam-se em torno de intencionalidades previamente estabelecidas, e tais intencionalidades serão perseguidas ao longo do processo didático, de formas e meios variados; $b-$ As práticas pedagógicas caminham por entre resistências e desistências; caminham numa perspectiva dialética, pulsional, totalizando; c - As práticas pedagógicas trabalham com e na historicidade; implicam tomadas de decisões, de posições e se transformam pelas contradições (FRANCO, 2016).
} 
A autora leva o leitor à reflexão do que são e como se constituem as práticas pedagógicas. Pautada em Carr (1996), Franco (2016) discute sobre o conceito de poesis (saber fazer) e o de práxis (ação reflexiva, consciente e participativa) pensando em práticas docentes construídas pedagogicamente. Coaduna com esse pensamento, Franco (2015, p. 601), quando apresenta a pesquisa-ação como pano de fundo para discutir outros elementos/aspectos da/na/pela prática pedagógica "na mediação com o outro, ou com os outros". Sempre ressignificando essas práticas pedagógicas (ação-teoria-prática) tendo em vista um rigor metódico e científico (FREIRE, 2011; 2014). A pesquisa-ação, assumida pela autora e por nós, é um procedimento que visa o engajamento, encorajamento e empoderamento na/pela e em cooperação do compartilhamento de saberes do/no e com o trabalho coletivo a fim de desenvolver o protagonismo e a autonomia docente e discente no/pelo e com os processos de ensinar e aprender na/pela interação com o outro.

Tal prática pedagógica pode funcionar como espaço onde circulam/caminham as resistências, desistências e as contradições (FRANCO, 2015; 2016), uma vez que estas se organizam em torno de intencionalidades. Ou seja, o professor precisa saber de onde está partindo e, para tanto, precisa ter bem claro seu viés epistemológico-teórico-metodológico para aonde quer/pretende chegar, o que deseja/almeja que seu aluno aprenda nessa mediação do conhecimento que é sempre dialógica e dialética na/pela relação eu-outro, outro-eu, eupara-mim (BAKHTIN, 2010; FREIRE, 2011; 2014).

Nas palavras de Franco (2016, p. 536), “as práticas pedagógicas se referem a práticas sociais que são exercidas com a finalidade de concretizar processos pedagógicos". Quanto às práticas educativas, estas fazem "referência a práticas que ocorrerem para a concretização dos processos educacionais" (FRANCO, 2016, p. 536). Práticas pedagógicas que requerem um diálogo crítico e reflexivo entre os múltiplos sujeitos, entre essas intencionalidades e essas ações. Qual é a intenção do professor com determinada prática? O que ele busca despertar no aluno? Aonde o aluno precisa chegar com essa prática? São algumas questões que emergem dos textos de Franco $(2015 ; 2016)$, reverberam na voz de Carvalho $(2019)^{5}$ e, que, ora atravessam também nosso discurso.

Tratam-se de ações de reflexão contínua e coletiva, consciente e participativa que constituem as subjetividades pedagógicas do professor na interação com o outro. Conforme assinala a autora, essa prática se materializa quando se dá voz e vez ao estudante, quando se leva em conta o seu lócus de fala, seu percurso histórico, a sua bagagem cultural, social, assim

${ }^{5}$ Docente da Unidade Curricular de Pesquisa e Prática Pedagógica I do Instituto Federal de Santa Catarina Campus Gaspar. 
como as suas vivências e as suas experiências na esfera escolar e para além dela. Logo, a intenção do ensino e das aprendizagens assentam-se na formação e na humanização das pessoas, do seu posicionamento, da sua tomada de decisões na/pela história, na/pela relação com o outro na/pelas contradições (FRANCO, 2015; 2016).

Outrossim, a Pedagogia compreendida a partir de uma racionalidade pedagógica técnico-científica como "transmissão de conteúdos instrucionais" (FRANCO, 2016, p. 537) está alicerçada em uma base positivista, tecnicista, mecanicista, pragmática do conhecimento científico e de mundo reduzindo-se ao conhecimento útil a partir de práticas normatizadoras e prescritivas (FREIRE, 2011; FRANCO, 2016). Ao contrário do que afirma Franco (2016, p. 537), quando parte de uma "epistemologia crítico-emancipatória, que considera ser a Pedagogia uma prática social conduzida por um pensamento reflexivo sobre o que ocorre nas práticas educativas, bem como por um pensamento crítico do que pode ser a prática educativa”. Portanto, a perspectiva crítica é constituída pela prática docente consciente, coletiva, ideológica, dialética em que sujeito e objeto estão em contínuo processo de formação na e pela história, sendo assim, "fruto das forças contraditórias que ocorrem no interior da própria realidade" (FRANCO, 2016, p. 539).

Neste sentido, depreende-se na voz da autora que a "prática docente é uma prática relacional, mediada por múltiplas determinações" (FRANCO, 2016, p. 540), assim como tal ato exige do professor planejamento, acompanhamento, responsabilidade social a fim de promover a transformação de si, do estudante e da realidade social. É importante que o professor se reconheça também nesse processo, uma vez que a educação está sempre sendo, é sempre processo, é histórica. Concebida como uma prática social humana, a educação, é inacabada, inconclusa, uma que vez que "o trabalho pedagógico requer espaço de ação e de análise ao não planejado, ao imprevisto, à desordem aparente" (FRANCO, 2016, p. 547). Considera-se assim, prática pedagógica só se efetiva na relação com outro (professor-aluno, aluno-professor), na/pelas e com as práticas sociais escolares e não escolares, a partir das "relações dialéticas pautadas nas mediações entre totalidade e particularidade" (FRANCO, 2016, p. 547), ou seja, entre o coletivo e o individual/singular, instigando/promovendo a emancipação, a criticidade e a inclusão de todos na esfera escolar e na sociedade (FREIRE, 2011; 2014; FRANCO, 2015; 2016).

O presente texto, embora, direcionado aos profissionais da educação, estudantes dos cursos de licenciatura e/ou cursos de pós-graduação em nível de especialização, mestrado e/ou doutorado e aos interessados pelo tema, apresenta discussões e reflexões teóricas pertinentes à realidade do público pretendido, isto pois, apesar de trazer uma escrita um pouco mais 
complexa, vai ao encontro das teorias e das práticas já vivenciadas por aqueles que optam por ler esse ensaio, que trata da prática pedagógica e docência. Enfatiza-se, assim, a relevância de sua contribuição na compreensão da constituição da subjetividade docente em diálogo com a prática pedagógica lançando olhar para uma dimensão mais alargada que considere os aspectos sociais, culturais e históricos desses sujeitos sempre em contínua formação, o professor e o estudante.

AGRADECIMENTOS: Agradecemos à professora do Instituto Federal de Santa Catarina Campus Gaspar, Dra. Giane Carmem Alves de Carvalho, pelas indicações de leitura, pelas interlocuções com os/as acadêmicos do curso de especialização em Pesquisa e Prática Docente (IFSC-Campus Gaspar). A todos/as os/as professores/as do IFSC-Campus Gaspar por promoverem um espaço de mediação, de compartilhamento de ideias, de conhecimento científico na e pela interação com o outro.

\section{REFERÊNCIAS}

BAKHTIN, Mikhail Mikhailovich. Estética da criação verbal. 6. ed. São Paulo: Martins Fontes, 2010.

FRANCO, Maria Amélia Santoro. Práticas pedagógicas de ensinar-aprender: por entre resistências e resignações. Educ. Pesqui., São Paulo, v. 41, n. 3, p. 601-614, jul./set. 2015. Disponível em: http://www.scielo.br/pdf/ep/v41n3/1517-9702-ep-41-3-0601.pdf. Acesso em: 13 jul. 2019.

FRANCO, Maria Amélia do Rosario Santoro. Prática pedagógica e docência: um olhar a partir da epistemologia do conceito. Rev. Bras. Estud. Pedagog., Brasília, v. 97, n. 247, p. 534-551, Dec. 2016. Disponível em:

http://www.scielo.br/scielo.php?script=sci_arttext\&pid=S2176-

66812016000300534\&lng=en\&nrm=is. Acesso em: 13 jul. 2019.

FREIRE, Paulo. Pedagogia da autonomia: saberes necessários à prática educativa. São Paulo: Paz e Terra, 2011.

FREIRE, Paulo. Pedagogia do oprimido. 56. ed. Rio de Janeiro: Paz e Terra, 2014.

SAVIANI, Dermeval. Pedagogia histórico-crítica: primeiras aproximações. 9. ed. Campinas: Autores Associados, 2005. 


\section{Como referenciar este artigo}

POTTMEIER, Sandra; SOUSA GUILHERME, Luiz Herculano de; FISTAROL, Caique Fernando da Silva. Prática pedagógica e docência: um olhar a partir da epistemologia do conceito. Doxa: Rev. Bras. Psico. e Educ., Araraquara, v. 21, n. 1, p. 182-186, jan./jun. 2019. e-ISSN: 2594-8385. DOI: https://doi.org/10.30715/doxa.v21i1.13038

Submetido em: 05/10/2018

Revisões requeridas: $22 / 11 / 2018$

Aprovado em: 01/12/2018

Publicado em: 01/02/2019 